\title{
High-fidelity Multipoint Aerostructural Optimization of a High Aspect Ratio Tow-steered Composite Wing
}

\author{
Timothy R. Brooks, * Joaquim R. R. A. Martins ${ }^{\dagger}$ \\ University of Michigan, Ann Arbor, Michigan, United States \\ Graeme J. Kennedy, \\ Georgia Institute of Technology, Atlanta, Georgia, United States
}

\begin{abstract}
Composite materials have been playing a major role in modern aircraft design due to their high stiffness and strength to weight ratio. While the advantages of composite structures over their metallic counterparts is significant, it is possible to improve even further on the benefits offered by traditional composites through the use of novel composite manufacturing methods. One such method is automated fiber placement, whereby each layer of the laminate is laid up with spatially steered fiber orientations, as opposed to the traditional method, where the fiber direction is fixed for each layer. While these new "tow-steered" composites can potentially provide additional aeroelastic tailoring when applied aircraft wing design, it is not clear how to fully take advantage of this new design freedom. To address this, we use high-fidelity gradient-based aerostructural optimization to assess the relative performance of tow-steered composites compared to conventional composites, as well as aluminum. The aircraft configuration used in this work is a high aspect ratio variant of the Common Research Model (CRM). When comparing the optimal conventional composite and optimal aluminum designs we find an improvement of roughly $8.7 \%$ in fuel burn and a $39 \%$ reduction in structural weight. The tow-steered designs yield improvements of $0.4 \%$ in fuel burn and $10 \%$ in structural weight when compared to conventional composites.
\end{abstract}

\section{Introduction}

Uncertainty of fuel prices coupled with a desire for more environmentally friendly transport aircraft has pushed the airline industry to continually demand for aircraft with improved fuel efficiency. This has resulted in aircraft designs with increasingly larger aspect ratio wings that reduce induced drag. Higher aspect ratio wings result in a stronger coupling between the aerodynamic and structural design disciplines due to the high degree of deflection seen in flight. While this represents a challenge, it can also be seen as a new opportunity for wing aeroelastic tailoring through passive load alleviation. Passive load alleviation consists of tailoring the wing deformation such that the aerodynamic loads are shifted inboard at conditions that are critical for the structure, while retaining an aerodynamically favorable lift distribution for cruise. Passive load alleviation is usually achieved by tailoring the structural properties of the wingbox. It has been shown that passive load alleviation is achievable for both metallic and composite designs through the use of gradient-based high-fidelity aerostructural optimization, $[1,2,3]$. With the advent of automated fiber placement (AFP) machines, we have now gained an additional design freedom in the local stiffness properties of our composite wings. It is therefore reasonable to expect that through the use of aerostructural optimization, we should achieve additional savings in aircraft performance with tow-steered composite designs through greater passive load alleviation.

Optimization of spatially varying composites is a topic that has been explored by various researchers. Hyvejsel et al. [4], Kennedy and Martins [5], and others have performed optimization of composite plates with spatially varying stiffness, by breaking the laminate up into a number of square patches each of which take on one of a number of discrete ply orientations $\left(0^{\circ}, \pm 45^{\circ}, 90^{\circ}\right.$, etc. $)$. The benefit that a tow-steered laminate would have over such a laminate is that the ply angles in theory are allowed to take any value and vary continuously through out the laminate. Jutte et al.[6] and Stodieck et al.[7] have explored some of the advantages of tow-steered composites when applied to the design of a composite wing. Jutte et al. demonstrated a 15\% decrease in structural weight and $47 \%$ decrease in aggregate stress relative to a conventional composite structure. These studies featured a medium-fidelity panel code coupled with a genetic algorithm to perform the optimization. The use of a genetic algorithm limited the number of design variables in the study to $\mathcal{O}(10)$. Stanford et al. [8] used gradient-based aerostructural optimization of tow-steered composite wings, but the aerodynamic analysis was limited to a low-fidelity panel method. In previous we extended

*Ph.D. Candidate, Department of Aerospace Engineering, AIAA Member

${ }^{\dagger}$ Professor, Department of Aerospace Engineering, AIAA Associate Fellow

${ }^{\ddagger}$ Assistant Professor, School of Aerospace Engineering, AIAA Member 
this study using gradient-based high-fidelity aerostructural optimization of a high aspect ratio tow-steered composite wing allowing for the performance of optimization with $\mathcal{O}(1000)$ design variables [9]. The wingbox in that study used unstiffened shells for the skins, spars, and ribs, because it was designed for a $27 \%$ scale structural experimental model that is being built by Aurora Flight Sciences, and is scheduled for static load and ground vibration tests (GVT) by NASA. In the present work, we seek to extend this study to a real aircraft by modeling and optimizing wingboxes with stringer-stiffened panels.

Kenway and Martins [1], Liem et al. [10], and Burdette et al. [11] found that while single-point high fidelity aerostructural optimization has the potential to improve on-design performance, multiple flight conditions must be considered in the optimization to ensure robustness of the design in off-design conditions. These previous studies focused on design optimization of conventional aluminum CRM-type geometries. The goal of the present work is to quantify the benefit of an unconventional tow-steered design relative to its conventional aluminum and composite counterparts for high aspect ratio wings.

The remainder of this paper is structured as follows. In Section II we give a brief overview of the framework used to perform the aerostructural optimization in this work. The high aspect ratio wing geometry used for this study is introduced in Section III. Then, the techniques used to parameterize and constrain the tow-steered and conventional designs is discussed in Section IV. We then describe the optimization problem considered for this work in Section V. Finally, the results are presented and discussed in Sections VI, followed by the conclusions in Section VII.

\section{Computational Framework}

As mentioned previously, to accurately assess the aeroelastic performance of high aspect ratio wings, a framework with a tightly coupled high fidelity aerodynamic and structural mechanics solver is necessary. All the results in this paper are obtained using the MACH (MDO for Aircraft Configurations with High fidelity) framework [2]. To perform aeroelastic analysis, MACH couples a computational fluid dynamics (CFD) solver to a computational structural mechanics (CSM) solver. A CFD mesh movement algorithm is used to handle the structural displacements and shape optimization changes. In this section we briefly overview each of these components of MACH; Kennedy and Martins [12] and Kenway et al. [13] provide a much more detailed description. MACH also features a shape parametrization algorithm that allows for the variation of aerodynamic shape of the wing during the optimization. Finally, this framework links the aerostructural solution to a gradient-based optimizer. MACH has been proven effective and efficient, enabling multiple high-fidelity aerostructural design studies [1, 14, 11,9].

To accurately capture the physics of the aerodynamics, a high-fidelity CFD solver is a necessity. The MACH Framework includes a second order finite-volume CFD solver, ADflow [15], which solves the steady ReynoldsAveraged Navier-Stokes (RANS) equations on structured multi-block meshes. In this work we use the single equation Spalart-Allmaras (SA) turbulence model. The CFD computes aerodynamic functions of interest, such as lift and drag. Thanks to the developments of Mader et al. [16] and Lyu et al. [17], and through the use of automatic differentiation, ADflow includes an adjoint solver that efficiently computes the sensitivities of force coefficients with respect to large numbers of design variables.

The high-fidelity CSM solver TACS (Toolkit for Analysis of Composite Structures) [18] computes the aerostructural deformations. TACS specializes in solving structures composed of thin shells, which are typical in aircraft structures. Through the use of a parallel direct factorization method, TACS is capable of accurately and efficiently solving the poorly conditioned problems associated with the type of structures typically seen in airframes. TACS is used to compute the structural functions of interest, such as displacements, buckling, and material failure functions [19, 20]. TACS also computes sensitivities of these functions with respect to large numbers of design variables efficiently using an adjoint method.

To couple the aerodynamics and structural solvers the wingbox structural deformations computed by the CSM solver must be propagated to the aircraft surface, and eventually to the whole CFD volume mesh. To move the volume mesh based on the new wing surface geometry, we use an inverse distance weighting mesh warping algorithm [21]. With this method, the quality of the mesh near the wing is maintained even for large deformations, which means that the accuracy and convergence rate of the CFD solver should not degrade as the aerostructural solution proceeds.

To converge the static aerostructural solution, we use a block Gauss-Seidel approach. In this method the aerodynamic loads computed by the CFD are passed as tractions to the CSM solver, which then computes the deflections. The structural deformations are then transferred to the surface of the wing using a series of rigid links between the nodes of the CFD mesh and their nearest neighbors in the CSM mesh [22]. The displacements from the surface of the wing are then extrapolated to the far-field of the CFD mesh using the mesh movement algorithm mentioned previously. The CFD is then solved again and the process is repeated until convergence. As was the case with the aerodynamic and structural solvers individually, MACH includes the adjoint of the coupled problem for efficient computation of 
sensitivities of aerostructural functions with respect to large numbers of design variables.

To perform shape optimization on the aerostructural problem we must have a way of parameterizing the geometry of the wing. In this work we use the free form deformation (FFD) algorithm, the implementation of which is described in detail by Kenway and Martins [1]. In this method the wing is embedded in a volume whose surface is covered with a number of control points. As the control points are moved the geometry encapsulated in the volume, the wing, deforms as well. This gives the optimizer an effective control over the shape of the wing. With this method not only can the cross-sectional shape of the wing be varied, but also the geometrical twist of the wing can be assigned at span-wise locations. In addition to the FFD volume placed on the wing there is an additional sub-FFD placed on the horizontal stabilizer to control the stabilizer incidence angle for the trimming of different flight configurations. The FFD model used for this study is shown in Figure 1

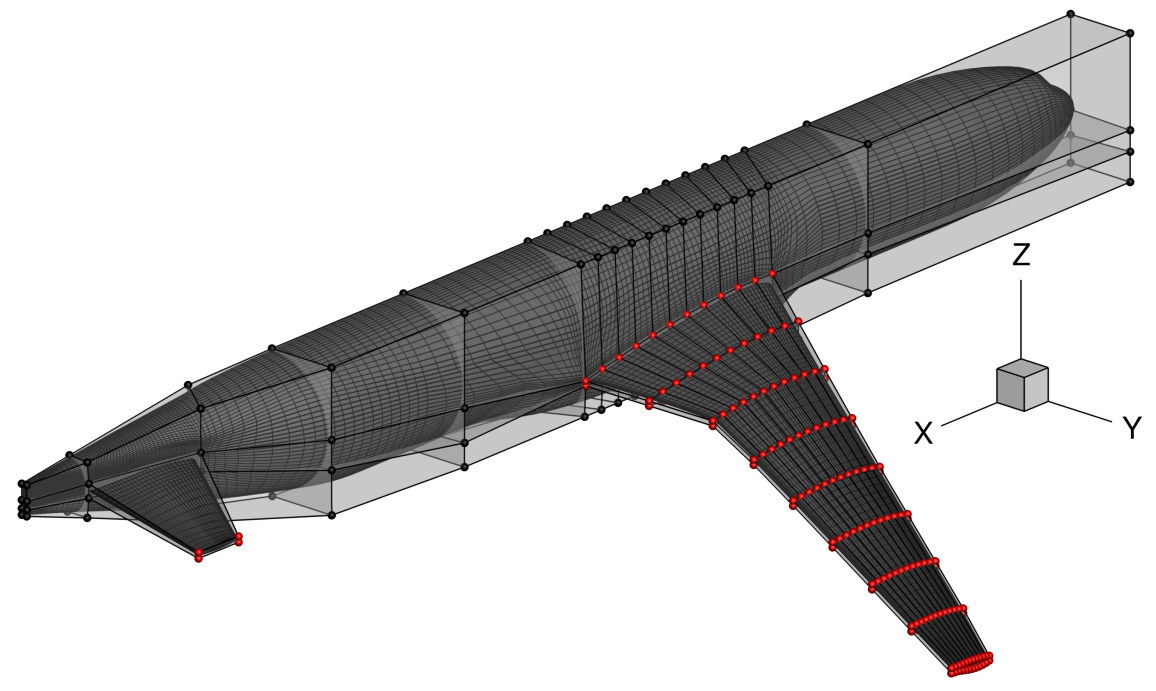

Figure 1. Free form deformation volume used for this work. The optimizer has control over the points in red.

For all the optimization herein, we use gradient-based optimization because the problems considered here features a large number of design variables $(\mathcal{O}(1000))$, which is intractable using gradient-free methods. It is for this reason that the solvers described above are developed to compute sensitivities with respect to large numbers of design variables for relatively low cost, using adjoint methods, and why the coupled-adjoint method is implemented in MACH [2]. All optimization problems in this work are performed using SNOPT (Sparse Nonlinear OPTimizer) [23], a quasi-Newton optimizer designed to perform well for optimization problems featuring many sparse nonlinear constraints. SNOPT is then wrapped by a Python interface using pyOpt [24], a Python interface to a suite of tools for nonlinear optimization problems.

\section{The uCRM-13.5 High Aspect Ratio Wing Configuration}

The optimizations for this study are conducted on the undeflected high aspect ratio version of the Common Research Model (uCRM-13.5). This is a variant of the NASA Common Research Model (CRM), originally developed by Vassberg et al. [25]. The uCRM-13.5 geometry is developed by taking the jig geometry for the original CRM and stretching the planform of the wing, while keeping the reference area constant. A multi-point aerostructural optimization was then performed on an aluminum design with consideration for buffet onset, similar to what was considered by Kenway and Martins [26], to define the cross-sectional and twist distribution of the wing. The geometry considered for this work includes the wing, fuselage, and horizontal stabilizer. The planform and wing box structure is shown in Figure 2. The wing box model includes a leading and trailing edge spar, 58 ribs, and skin panels. The stiffeners are not modeled explicitly in the finite-element model; instead, they are accounted for by homogenizing their stiffness properties into the skin and parameterizing the stiffener height and thickness. The material properties for the aluminum design and composite designs are listed in Tables 1 and 2, respectively.

In this work only static aeroelastic effects of the wing are considered, and the rest of the components in the model are assumed to be rigid. The inertial of effects of non-structural masses attached to the wing structure are also accounted for in the model. These masses include a 7,500 kg engine along with a number of leading edge and trailing 
Table 1. Mechanical properties for the aluminum design

\begin{tabular}{lrlr}
\hline Parameter & Value & Parameter & Value \\
\hline$E$ & $70 \mathrm{GPa}$ & $\nu$ & 0.3 \\
$\sigma_{\mathrm{YS}}$ & $420 \mathrm{MPa}$ & $\rho$ & $2780 \mathrm{~kg} / \mathrm{m}^{3}$ \\
\hline
\end{tabular}

Table 2. Mechanical properties for the composites used on skin, ribs, and spars

\begin{tabular}{|c|c|c|c|c|c|c|c|c|c|c|c|c|}
\hline Material & $\begin{array}{r}E_{1} \\
{[\mathrm{GPa}]}\end{array}$ & $\begin{array}{r}E_{2} \\
{[\mathrm{GPa}]}\end{array}$ & $\begin{array}{r}G_{12} \\
{[\mathrm{GPa}]}\end{array}$ & $\begin{array}{r}G_{13} \\
{[\mathrm{GPa}]}\end{array}$ & $\begin{array}{r}G_{23} \\
{[\mathrm{GPa}]}\end{array}$ & $\nu_{12}$ & $\begin{array}{r}X_{t} \\
{[\mathrm{MPa}]}\end{array}$ & $\begin{array}{r}X_{c} \\
{[\mathrm{MPa}]}\end{array}$ & $\begin{array}{r}Y_{t} \\
{[\mathrm{MPa}]}\end{array}$ & $\begin{array}{r}Y_{c} \\
{[\mathrm{MPa}]}\end{array}$ & $\begin{array}{r}S \\
{[\mathrm{MPa}]}\end{array}$ & $\begin{array}{r}\rho \\
{\left[\mathrm{kg} / \mathrm{m}^{3}\right]}\end{array}$ \\
\hline Unidirectional tape E752LT/AS4 (Skin) & 117.9 & 9.7 & 4.8 & 4.8 & 4.8 & 0.34 & 1648 & 1034 & 64 & 228 & 71 & 1550 \\
\hline PW Fabric AS4/8552 (Ribs and Spars) & 62.1 & 62.1 & 5 & 4.8 & 4.8 & 0.045 & 279 & 266 & 279 & 266 & 70 & 1550 \\
\hline
\end{tabular}

edge masses that account for the non-structural weight of the wing, as shown in Figure 2. The engine is mounted on the leading edge spar and a mounting panel between two rib members. Since we are performing only static aeroelastic analysis, the inertial effect of the engine is concentrated at its center of mass and then linked to the mounting locations using a rigid element. The inertial effect of the fuel weight in the wing is also modeled through the use of a distributed traction on the lower skin of the wing box.

The CFD model for the optimization includes a coarse grid, used for the maneuver conditions where drag accuracy is not important, and a finer grid, for the cruise conditions where the accuracy of the drag values is important. The coarse and fine grids feature a total of 740192 and 1779200 cells, respectively. The solution for the model at nominal cruise condition $\left(C_{L}=0.515, M=0.85\right.$, Alt $\left.=37000 \mathrm{ft}\right)$ is shown in Figure 3. The structural finite-element model consists of 24071 MITC4 shell elements, with 23738 nodes, and roughly 136000 degrees of freedom.

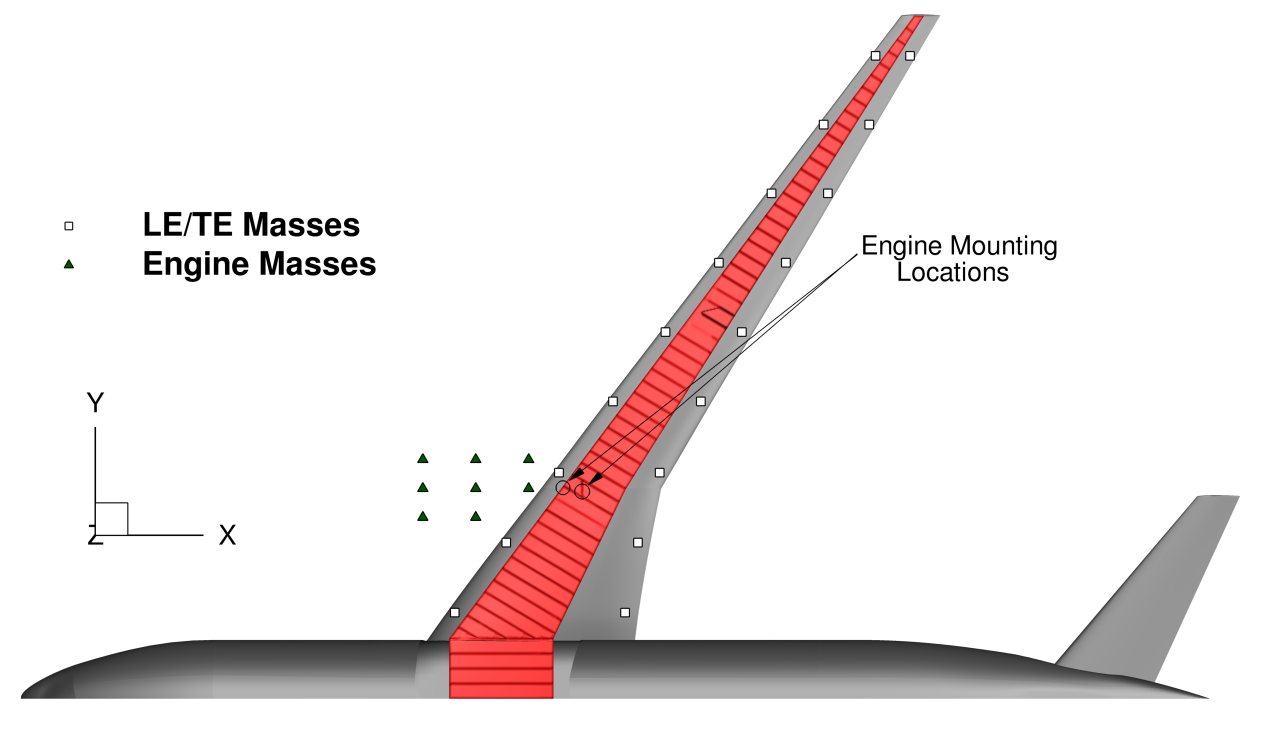

Figure 2. uCRM-13.5 planform and wing box with non-structural masses

\section{Structural Parameterization}

In this section we will describe the structural parameterization of the conventional aluminum, composite, and towsteered composite wing boxes. The stiffness of the wing box panels is modeled using a smeared stiffness approach, as described by Kennedy et al. [27]. Using this method, the effect of the stiffeners is homogenized into the stiffness properties of the panel. This model assumed that the density of the stiffeners is high relative to the panel bay dimensions, and that the wingbox panels have a cross-section as shown in Figure 4. For simplicity, we assumed that $t_{w}=t_{b}$ and $w_{b}=h_{s}$. This allows us to avoid having to explicitly include stiffener geometries in the structural model.

To avoid the issues in dealing with the discrete nature of the composite stacking sequence, the stiffness of the laminate is homogenized through the thickness based on the fractions of plies at each angle through the thickness of the laminate. This neglects the effect of stacking sequence on the bending stiffness of the laminate, but works 


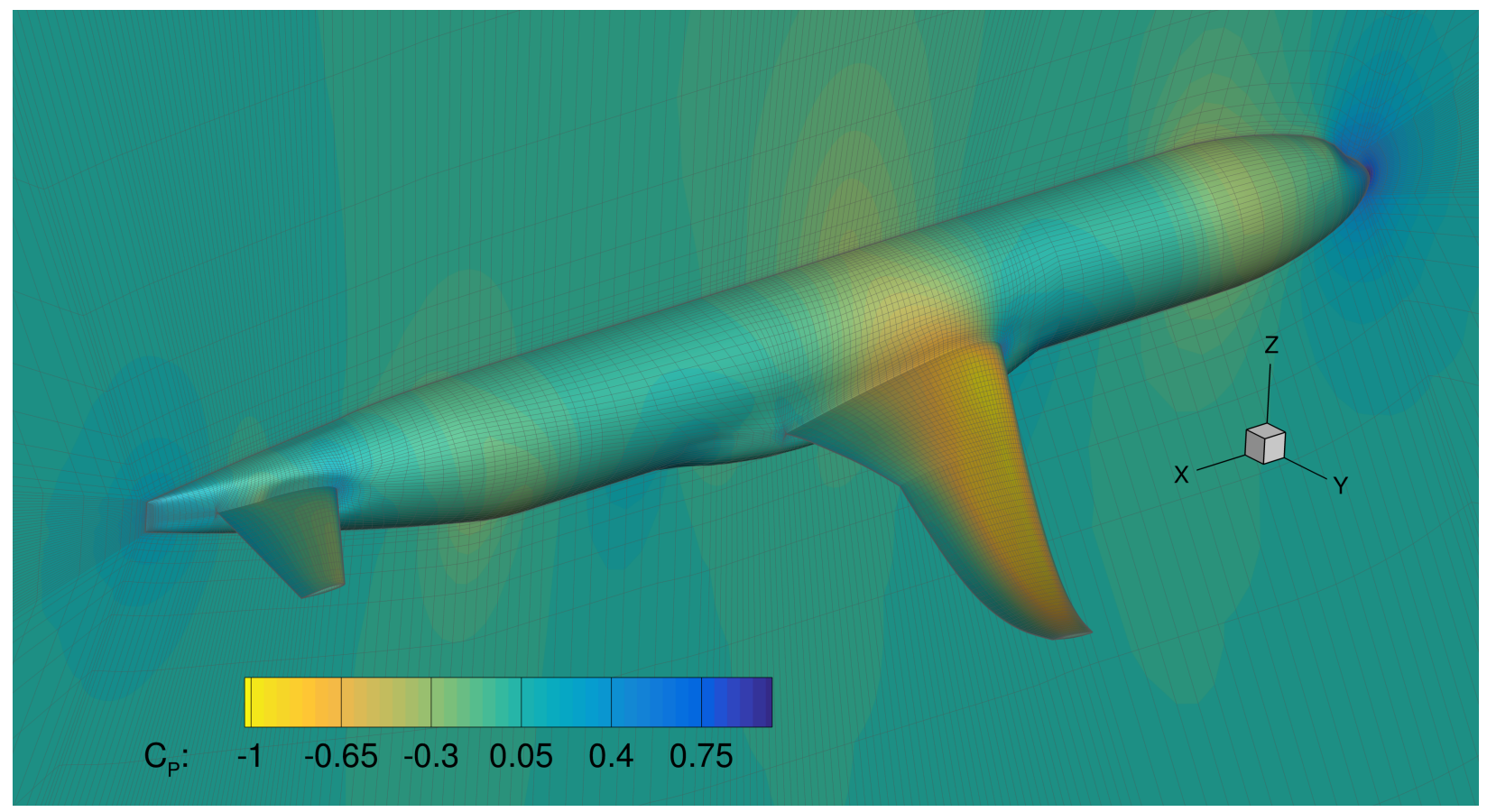

Figure 3. uCRM-13.5 nominal cruise condition solution on fine grid mesh

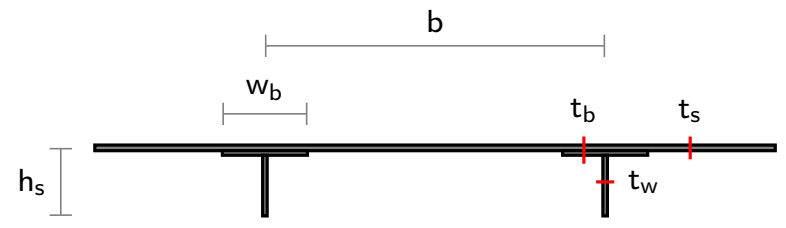

Figure 4. General panel-stiffener cross-section parametrization assumed by the smeared stiffness approach [27].

well for thick laminates. In the case of the conventional composite structure, there are four allowable ply orientations $\left(-45^{\circ}, 0^{\circ}, 45^{\circ}, 90^{\circ}\right)$. The distribution for the tow-steered laminate is similar; however, the angles are now offset by an angle that varies parametrically through the skin of the wing box $\left(\theta_{0}(u, v)-45^{\circ}, \theta_{0}(u, v), \theta_{0}(u, v)+45^{\circ}, \theta_{0}(u, v)+\right.$ $90^{\circ}$ ), where $u$, and $v$ are parameteric coordinates describing the wing box surface. This results in four unique steered patterns on each skin that are repeated throughout the layup procedure of each skin at a frequency corresponding to their ply fraction. The reason for doing this is to ensure one dominant steered pattern, with three other offset patterns to ensure some off-axis strength. In this work, the ply fractions for both composite designs (conventional and tow-steered) are fixed for the optimization to $(12.5 \%, 62.5 \%, 12.5 \%, 12.5 \%)$ for each respective ply orientation. For the conventional wingboxes, the structural design variables - panel thickness, stiffener height and thickness—are assigned to each structural patch on the wing box model, as shown in Figure 5. This restriction is relaxed for the towsteered design and the panel thickness is allowed to vary continuously and parametrically across the skins, in order to represent the continuous nature of the AFP layup process. In the case of the tow-steered design, the tow-orientation offset, $\theta_{0}(u, v)$, and local panel thickness, $t(u, v)$, are set using B-spline control points distributed along the skins of the wing box. Figure 6 shows an example tow-steered layup for one of the wing box skins. The remaining design variables on the tow-steered model, stiffener thickness and height, are set at the wingbox structural patches, since only the skins are assumed to be steered.

\section{A. Failure analysis}

For the optimization, we must prevent material failure at any point in the structure for each flight condition through stress and buckling constraints. In this work, the stress constraints are enforced both for the wing box panels and for 


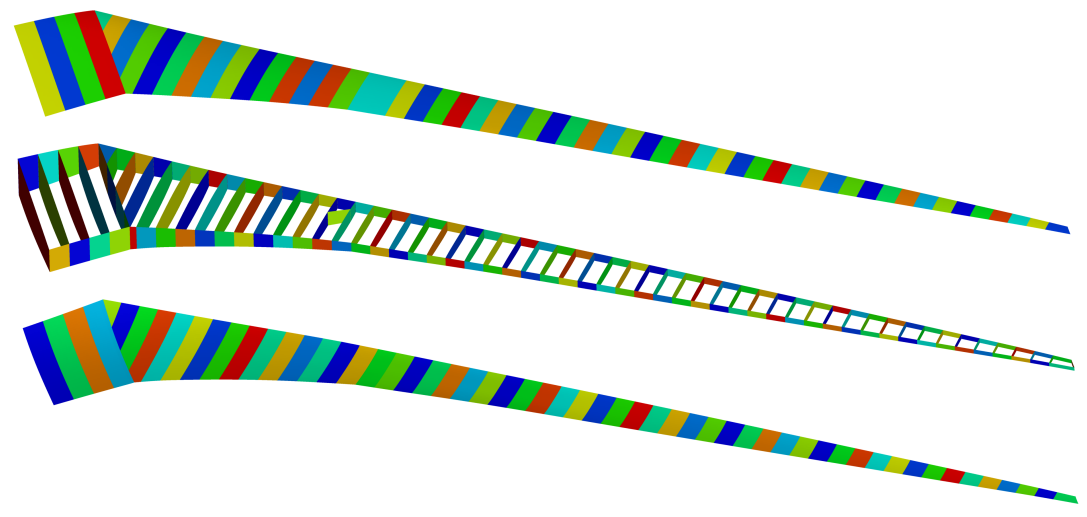

Figure 5. Structural parametrization for the conventional designs. Each patch consists of 3 structural design variables.

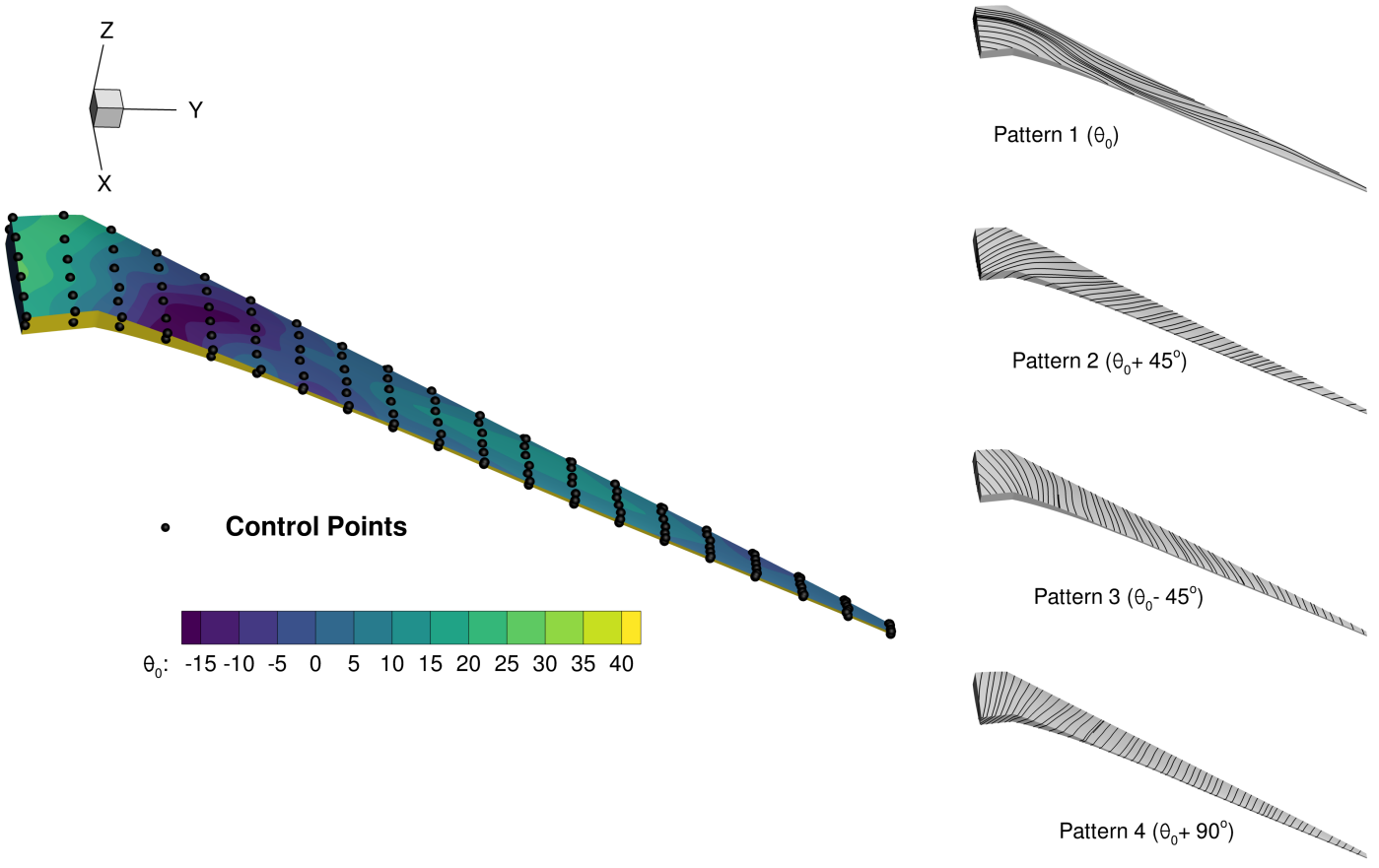

Figure 6. Structural parametrization used to define tow patterns and skin thickness on tow-steered design 
the stiffeners. For the aluminum design, we use the von Mises failure criterion. For the composite designs, we use a maximum strain criterion. The failure constraint is evaluated at the outer most layers of the panels, and the bottommost layer of the stiffener. For the composite designs, the constraint is applied as a first-ply failure where the all plies $\left(-45^{\circ}, 0^{\circ}, 45^{\circ}, 90^{\circ}\right)$ must be tested to ensure none of them fail. Once the failure constraint has been computed, it is then aggregated using a Kreisselmeier-Steinhauser (KS) function [28, 29] over the ribs, spars, and each skin of the wing box.

\section{B. Buckling analysis}

In order to size the wingbox correctly, we must also prevent buckling. This is done through a simplified panel-level buckling analysis of the stiffened panels. This buckling analysis considers several different buckling modes, including: inter-stiffener panel buckling, stiffener buckling, and global panel buckling. Once the buckling values are known, an envelope is defined such that the stress values do not exceed the critical buckling loads anywhere in the panel. Similarly to the failure constraint, the buckling constraint is aggregated over each component using a KS function. More details of this approach are provided by Kennedy et al. [27].

\section{Manufacturing constraints}

Three manufacturing constraints are considered for the tow-steered design: fiber path turning radius, tape gaps and overlaps, and ply drop rate. A minimum fiber path turning radius is a typical manufacturing constraint when designing tow-steered laminates. The reason for this is that as the AFP machine lays down the pre-preg tape, highly curved regions of the laminate have a tendency to cause the tape to pucker out on the edges or roll over on itself as it is being laid down. The fiber path turning radius is found by first computing the magnitude curl of the tangent vector field defining the fiber path of each pattern of the steered skins.

$$
\kappa(u, v)=\|\nabla \times \vec{s}(\theta)\|,
$$

where $\vec{s}(\theta)$ is the vector field defining the fiber path for each layer of the steered skins. It can be shown that this value, $\kappa$, is equivalent to the curvature of the fiber path, so by taking the inverse of the value we recover the turning radius.

As the AFP machine lays up the steered laminate, there will be regions in each layer where no tape is placed or in which two adjacent tapes are overlapping. If these regions occur too frequently, there can be a significant departure from the local stiffness and mass properties of the idealized model. For this reason, we must constrain the amount of gaps and overlaps. We do this by taking the divergence of the tangent vector field, i.e.,

$$
\psi(u, v)=\nabla \cdot \vec{s}(\theta)
$$

Since vector divergence is a measurement of how quickly adjacent paths are approaching or separating from each other, high divergence regions correlate with regions with excessive gaps and overlaps. This means that by constraining the magnitude of the fiber path divergence, we constrain the degree to which gaps and overlaps occur in the manufactured panels.

Finally, the ply drop rate is also constrained to ensure that the laminate thickness does not change too abruptly. This is controlled by constraining the magnitude of the thickness gradient, $\|\nabla t(u, v)\|$. Similarly to the failure and buckling constraints, these manufacturing constraints are evaluated at the centroid of each element and then aggregated over each panel the steered skin using a KS function. More details on the implementation and relationship of these constraints can be found in previous work published by the authors [9].

\section{Optimization Problem Description}

In this section we describe the optimization problems that we solved by detailing the objective function, design variables, and constraints that are enforced. As mentioned previously, three multipoint aerostructural optimization designs are considered: conventional aluminum, composite, and tow-steered composite. This is done to assess the performance of two conventional designs, aluminum and composite, compared to the unconventional tow-steered design. Multiple flight conditions are considered to ensure robustness of the optimal configurations for off-design conditions. Each optimization features five cruise conditions used to evaluate the average fuel burn performance of the design, and two maneuver conditions: a $2.5 \mathrm{~g}$ pull up and $-1.0 \mathrm{~g}$ push over maneuver, for structural sizing. The specifics of the flight conditions are listed in Table 3. The first point of the cruise stencil was defined as the nominal cruise condition of the CRM (Mach $=0.85, C_{L}=0.5$ ). Points 2 and 3 were defined as \pm 0.025 offsets in $C_{L}$ relative to point 1 . Cruise points 4 and 5 are \pm 0.01 offsets in Mach number relative to point 1 , but restricted to have the same dimensional lift. All cruise conditions are evaluated at an altitude of $37000 \mathrm{ft}$, while the maneuver conditions are evaluated at sea level. A full description for the optimization problem is given in Table 4. 
Table 3. Optimization flight condition parameters

\begin{tabular}{lrrrrr}
\hline Point & Condition & FB Weight $\left(T_{i}\right)$ & Mach & $C_{L} /$ Lift & Altitude $(\mathrm{ft})$ \\
\hline 1 & Cruise & $\frac{1}{5}$ & 0.85 & 0.5 & 37000 \\
2 & Cruise & $\frac{1}{5}$ & 0.85 & 0.475 & 37000 \\
3 & Cruise & $\frac{1}{5}$ & 0.85 & 0.525 & 37000 \\
4 & Cruise & $\frac{1}{5}$ & 0.84 & 0.512 & 37000 \\
5 & Cruise & $\frac{1}{5}$ & 0.86 & 0.488 & 37000 \\
6 & 2.5 g Maneuver & 0 & 0.64 & $2.5 \cdot$ TOGW & 0 \\
7 & -1.0 g Maneuver & 0 & 0.64 & TOGW & 0 \\
\hline
\end{tabular}

\section{A. Objective}

As mentioned previously, the objective of each optimization is to minimize the average fuel burn over all five cruise conditions. The fuel burn for each flight condition, $\mathrm{FB}_{i}$, is computed using the Breguet,

$$
\mathrm{FB}_{i}=\mathrm{LGW}\left(\exp \left(\frac{R \mathrm{TSFC}}{V_{i}(L / D)_{i}}\right)-1\right),
$$

where LGW, $R$, and TSFC are the landing weight of the aircraft, total range of the mission, and thrust specific fuel consumption of the engine, respectively. These values are assumed to be the same between all five cruise conditions. $V_{i}$ and $L / D_{i}$ are the cruise velocity and lift to drag ratio for the $i$-th cruise condition, respectively. To account for the drag of the missing components in the model, such as the vertical stabilizer, engine, and engine pylon, an additional 40 drag counts are added to the results of the drag provided by the CFD solution. For simplicity only fuel burned during cruise is considered. The landing weight is computed as follows:

$$
\text { LGW }=1.25 \times W_{\text {wing }}+\text { Fixed Weight }+ \text { Reserve Fuel Weight }+ \text { Secondary Wing Weight, }
$$

where the weight of the wing box, $W_{\text {wing }}$, is computed from the CSM finite-element model and then multiplied by a factor of 1.25 to account for more detailed components missing from the model such as fasteners, and access bay reinforcements.

\section{B. Design Variables}

The design variables we use can be broken down into three basic types: aerodynamic, geometric, and structural. All three designs share the same aerodynamic and geometric variables, while the structural variables differ between the conventional designs (aluminum and composite) and the unconventional tow-steered composite, as described in Section IV.

The aerodynamic design variables for these problems include the angle of attack for each flight condition, which is needed to allow the optimizer to satisfy the lift constraint for each flight condition. Since there is an angle of attack for each condition the total number of these variables is 7 . The second aerodynamic design variable is the horizontal tail incidence angle for each flight condition, which is controlled by rotating a sub-FFD volume placed on tail. This variable is added to allow the optimizer to trim each flight condition about the pitching axis.

The next group of design variables are the geometric variables, which are controlled through the FFD control points shown in Figure 1. The first of these variables are the shape variables that control the cross-sectional shape of the wing by varying the $z$ coordinates of the 240 FFD control points on the wing. The geometric variables also include twist variables, which control the twist distribution at 8 span-wise locations along the wing.

Finally, the structural variables include panel thickness, stiffener height, and stiffener thickness for each panel shown in Figure 5, for a total of 287 for each of these types of variables. Each patch also features a panel length variable that is used to used in the prediction of the analytical panel buckling formulas. There is a consistency constraint that is applied to ensure that this panel length variable matches the physical dimensions of each patch. The stiffener spacing is also a design variable; it is implemented so that the upper skin, lower skin, ribs, and spars share one value each, for a total of 4 .

The difference for the tow-steered design is that the panel thickness is set parametrically using $120 \mathrm{~B}$-spline control points distributed over each skin, and 20 control points distributed over each spar. This means 280 panel thickness control point variables and leaves 58 panel thickness variables for the ribs. In addition the tow-steering model also includes the tow-offset control point variable, $\theta_{0}^{\mathrm{cp}}$, on either skin, for a total of 240 variables. 


\begin{tabular}{|c|c|c|c|c|}
\hline & Variable/function & Description & $\begin{array}{c}\text { Tow-Steered } \\
\text { variables \# }\end{array}$ & $\begin{array}{c}\text { Conventional } \\
\text { variables \# }\end{array}$ \\
\hline Minimize & $\sum_{i=1}^{N} T_{i} \mathrm{FB}_{i}$ & Average fuel Burn & & \\
\hline \multirow[t]{13}{*}{ with respect to } & $x_{\alpha_{i}}$ & Angle of attack for each case & 7 & 7 \\
\hline & $x_{\text {tail }}$ & Tail trim angle for each case & 7 & 7 \\
\hline & $x_{\text {shape }}$ & FFD control points & 240 & 240 \\
\hline & $x_{\text {twist }}$ & Wing twist & 8 & 8 \\
\hline & $x_{t}$ & Panel thickness Skin/Spars & 0 & 229 \\
\hline & $x_{\text {ribs }}$ & Panel thickness Ribs & 58 & 58 \\
\hline & $x_{\text {stiff thick }}$ & Panel stiffener thickness Skin/Spars/Ribs & 287 & 287 \\
\hline & $x_{\text {stiff height }}$ & Panel stiffener height Skin/Spars/Ribs & 287 & 287 \\
\hline & $x_{\text {stiff pitch }}$ & Panel stiffener pitch & 4 & 4 \\
\hline & $x_{\text {panel length }}$ & Panel length Skin/Spars/Ribs & 287 & 287 \\
\hline & $x_{t^{\mathrm{cp}}}$ & Skin/Spar panel thickness control points & 280 & 0 \\
\hline & $x_{\theta_{0}^{\text {cp }}}$ & Skin tow offset control points & 240 & 0 \\
\hline & & Total design variables & 1705 & 1414 \\
\hline \multirow[t]{20}{*}{ Subject to } & $C_{L_{i}}=C_{L_{i}}^{*}$ & Cruise lift conditions & 5 & 5 \\
\hline & $L=n_{i} \mathrm{TOGW}_{0}$ & Maneuver lift conditions & 2 & 2 \\
\hline & $c_{m_{y}}^{i}=0$ & Trimmed flight & 7 & 7 \\
\hline & $t_{L E} / t_{L E_{\text {init }}} \geq 1.0$ & Leading edge radius & 20 & 20 \\
\hline & $t_{T E} / t_{T E_{\text {init }}} \geq 1.0$ & Trailing edge thickness & 20 & 20 \\
\hline & $(t / c)_{\mathrm{TE} \mathrm{Spar}} \geq 0.80(t / c)_{\mathrm{TE} \text { spar }_{\text {init }}}$ & Minimum trailing edge spar height & 20 & 20 \\
\hline & $\Delta z_{\mathrm{TE}, \text { upper }}=-\Delta z_{\mathrm{TE}, \text { lower }}$ & Fixed trailing edge & 8 & 8 \\
\hline & $\Delta z_{\mathrm{LE}, \text { upper }}=-\Delta z_{\mathrm{LE}, \text { lower }}$ & Fixed leading edge & 8 & 8 \\
\hline & $V-V_{\text {fuel }} \geq 0.0$ & Minimum fuel volume & 1 & 1 \\
\hline & $L_{\text {panel }}-x_{\text {panel length }}=0$ & Target panel length & 266 & 266 \\
\hline & $\mathrm{KS}_{\text {stress }}<1.0$ & $2.5 \mathrm{~g}$ Material Failure & 4 & 4 \\
\hline & $\mathrm{KS}_{\text {buckling }}<1.0$ & $2.5 \mathrm{~g}$ and $-1.0 \mathrm{~g}$ Buckling & 6 & 6 \\
\hline & $\left|x_{\text {panel thick }_{i}}-x_{\text {panel thick }_{i+1}}\right| \leq 0.0005$ & Skin thickness adjacency & 0 & 258 \\
\hline & $\left|x_{\text {stiff thick }_{i}}-x_{\text {stiff thick }_{i+1}}\right| \leq 0.0005$ & Stiffener thickness adjacency & 258 & 258 \\
\hline & $\left|x_{\text {stiff height }_{i}}-x_{\text {stiff height }_{i+1}}\right| \leq 0.0005$ & Stiffener height adjacency & 258 & 258 \\
\hline & $\left|x_{\text {stiff thick }}-x_{\text {panel thick }}\right|<0.0025$ & Maximum stiffener-skin difference & 172 & 172 \\
\hline & $-\frac{1}{r_{\min }}<\mathrm{KS}_{\kappa}<\frac{1}{r_{\min }}$ & Fiber path turning radius & 112 & 0 \\
\hline & $-\psi_{0}<\mathrm{KS}_{\psi}<\psi_{0}$ & Fiber path divergence & 112 & 0 \\
\hline & $\mathrm{KS}_{\|\nabla t\|}<\left\|\nabla t_{0}\right\|$ & Panel thickness variation & 221 & 0 \\
\hline & & Total constraints & 1440 & 1253 \\
\hline
\end{tabular}

Table 4. Aerostructural optimization problem formulations 
Table 5. Objective parameters

\begin{tabular}{lrl}
\hline Parameter & Value & Units \\
\hline Design range & 7725 & $\mathrm{~nm}$ \\
Design payload & 34000 & $\mathrm{~kg}$ \\
Reserve fuel & 15000 & $\mathrm{~kg}$ \\
Fixed weight & 107814 & $\mathrm{~kg}$ \\
Thrust specific fuel consumption (TSFC) & 0.53 & $\mathrm{lb} /(\mathrm{lbf} \cdot \mathrm{h})$ \\
\hline
\end{tabular}

\section{Constraints}

In order for the optimizations to be well posed and to obtain practical results, a number of constraints are required. The first set of constraints enforce that the $C_{L}$ of each cruise condition match the required value given in Table 3 . The next set of constraints ensures that the lift at each maneuver condition equals the takeoff gross weight computed for the nominal cruise condition, $\mathrm{TOGW}_{0}$, multiplied by their respective load factors. We also add a constraint on the pitching moment of each flight condition to enforce trimmed flight.

The leading edge radius of the wing is constrained from decreasing, in order to maintain high lift performance of the aircraft. The trailing edge and spar thickness are constrained as well to ensure manufacturability of the wing. The positions of the leading edge and trailing edge are also forced to be fixed with respect to the cross-sectional shape variables. This prevents the shape variables from inadvertently introducing additional twist into the geometry, which should be the sole responsibility of the twist variables. The volume of the wing box is also constrained to be large enough to fit the volume of the fuel computed from the fuel burn calculation plus reserve fuel.

The remaining constraints pertain to the structure of the wing box. For structural sizing purposes, all three designs are constrained to avoid material failure or panel buckling during any of the maneuver conditions, to within a safety factor of 1.5. Several hundred adjacency constraints are placed on the panel thickness, stiffener thickness, and stiffener height of adjacent structural patches to ensure that the structure does not vary to abruptly. Lastly, we have the tow-steering manufacturing constraints, which only apply to the tow-steered optimization problem. These include a constraint on the fiber path turning radius of each pattern, which is constrained to a minimum allowable turning radius, $r_{\min }$, of $70 \mathrm{in}$. This value is determined from a manufacturers recommendation for a $0.5 \mathrm{in}$ wide pre-preg tape. For simplicity the maximum allowable fiber path divergence magnitude, $\psi_{0}$, is constrained to $\frac{1}{r_{\min }}$. Lastly, there is a constraint on the the thickness gradient, which is the continuous analogue to the discrete adjacency constraint applied to the panel thickness in the conventional designs. The maximum thickness gradient value, $\left\|\nabla t_{0}\right\|$ is set to $1.3 \frac{\mathrm{mm}}{\mathrm{m}}$, a value chosen to be representative of the discrete adjacency thickness constraints on the conventional designs.

\section{Results}

The convergence history for each optimization is shown in Figure 7. The feasibility and optimality measure the magnitude of total constraint violation and satisfaction of the first-order Karush-Kuhn-Tucker (KKT) conditions, respectively, during the optimization [30]. From these optimization histories we can see that the convergence gradually before hitting their respective exit conditions. This gradual convergence is likely due to the highly coupled nature of the aerodynamic and structural disciplines featured in these problems.

The results for the conventional aluminum optimization are shown in Figure 8. The baseline uCRM-13.5 is used as a reference for the aluminum optimized design. The results from the conventional composite and the tow-steered optimization are shown in Figure 9. It is not surprising to see that all three cases-aluminum, conventional composite, and tow-steered composite-outperform the uCRM-13.5 baseline design. We can see that all designs feature a smooth $C_{p}$ distribution over the upper wing surface, which is aerodynamically beneficial. The average fuel burn for the aluminum, conventional composite, and tow-steered composite designs are $87,188 \mathrm{~kg}, 79,618 \mathrm{~kg}$, and $79,376 \mathrm{~kg}$ respectively. This represents an improvement of $8.7 \%$ in fuel burn performance of the conventional composite compared to the aluminum design. The fuel burn improvement between the aluminum design to the conventional composite agrees well with results found by Kennedy et al. [31] when comparing fuel burn performance of single-point optimized aluminum and composite high aspect ratio wing designs.

When comparing the fuel burn between the two composite designs we find that tow-steering offers a much smaller reduction in fuel burn of $0.4 \%$. We also find similar improvements in takeoff gross weights for each design: $284,013 \mathrm{~kg}, 263,179 \mathrm{~kg}$, and $260,803 \mathrm{~kg}$. This is an improvement of $7.3 \%$, when comparing composite with aluminum, and a $0.9 \%$ improvement between the tow-steered and conventional composite designs. We see a more significant improvement when looking at the structural wing weight of the three designs: $33825 \mathrm{~kg}, 20561 \mathrm{~kg}$, and 
$18426 \mathrm{~kg}$. This corresponds to a reduction of $39 \%$ when comparing the conventional composite to the aluminum wing, and a $10 \%$ reduction between the tow-steered wing and the conventional composite one. This $10 \%$ reduction in structural weight over the conventional design agrees well with results we found in a previous study of a single-point optimization of an unstiffened tow-steered wing [9]. Interestingly, when it comes to aerodynamic performance, the conventional composite design has a slightly better $L / D$ despite having a higher fuel burn. This means that the slight improvement seen in fuel burn on the tow-steered design is due primarily to the reduction in structural weight of the wing box, and that the optimizer decides to trade some aerodynamic performance to reduce the structural weight.
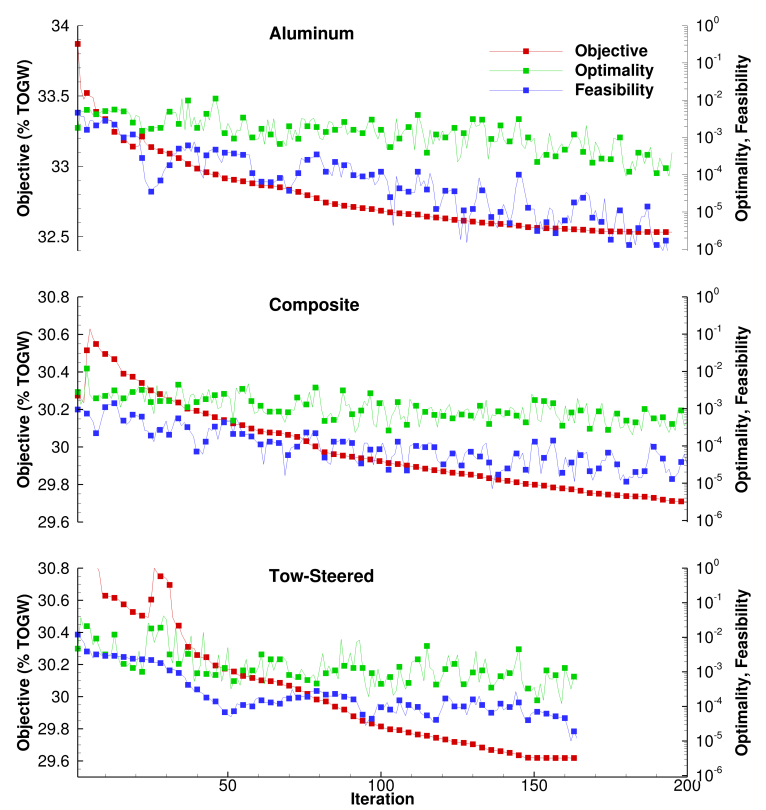

Figure 7. Optimization convergence histories for the each cases

Analyzing the normalized lift distribution, we can infer more about the trends that drive the optimization. Firstly, in all three cases the optimizer attempts to achieve a more elliptical lift distribution to reduced the induced drag during cruise flight. On the $2.5 \mathrm{~g}$ maneuver condition, load is shifted from the tip inboard, resulting in a bell-shaped lift distribution. This reduces the bending moment at the root of the wing, which reduces the wingbox internal forces, thus requiring less material for a given strength. Thus, our aerostructural optimization naturally takes advantage of passive load alleviation.

In spite of the use of passive load alleviation for all optimal designs, we see little difference in the lift distributions of the two composite designs. This means that the reduction in structural weight is likely caused by a different structural mechanism. Analyzing the thickness-to-chord distributions of the designs we can see that the overall trend remains the same between the three designs.

The buckling and material failure constraints are shown in the top right corners of Figures 8 and 9. Based on these results, we see that the buckling constraint is actively sizing most of the upper skin of the wing box for all three designs, while material failure on this condition largely sized the lower skin, spars, and ribs. In Figure 10, we can see the optimized layups of the conventional composite and tow-steered designs. By looking at the panel thickness distribution we can see that the tow-steered structure is noticeably thinner near the root on both the skins and spars, which accounts for the difference in structural weight. This is likely due to the optimizer taking advantage of the fiber steering to locally shift the load paths of the wing and aligning fiber paths closer to local principal stress directions. Toward the tip of the structure the dominate steering pattern, pattern 1, sweeps forward toward the leading edge. This provides two benefits: an increase in torsional stiffness and bend-twist coupling. These results indicate that the improvement in structural weight of the tow-steered design is driven mostly by local effects, reducing local panel buckling and aligning fibers with local load paths, rather than by global effects, such as passive load alleviation. This is similar to what was found by Stanford et al. [8] using a lower-fidelity optimization of a tow-steered wing. 
$\begin{array}{ll}\text { Baseline Aluminum } & \text { Aluminum Optimized } \\ \text { Avg. Fuel burn: } 87188 \mathrm{~kg}\end{array}$ Avg. TOGW: $289868 \mathrm{~kg}$

Wing mass: $36722 \mathrm{~kg}$

Avg. L/D: 21.53

N

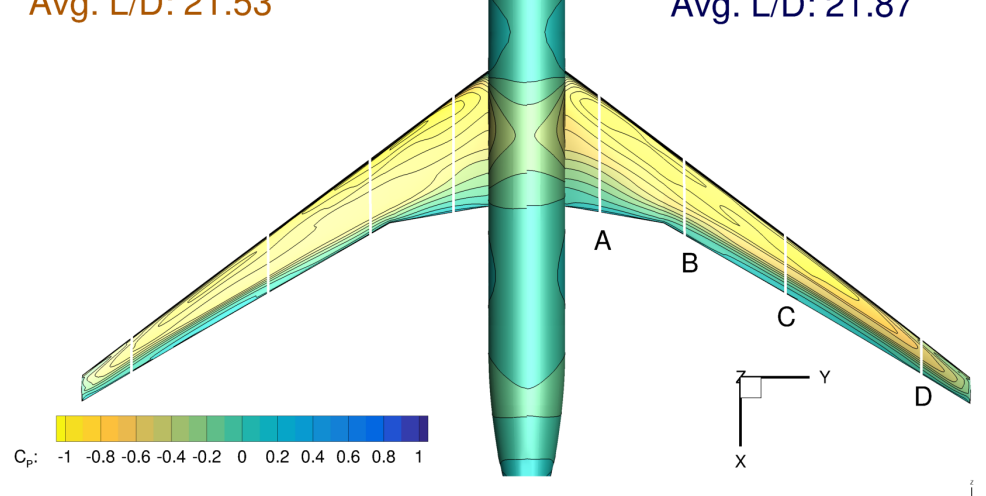

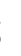
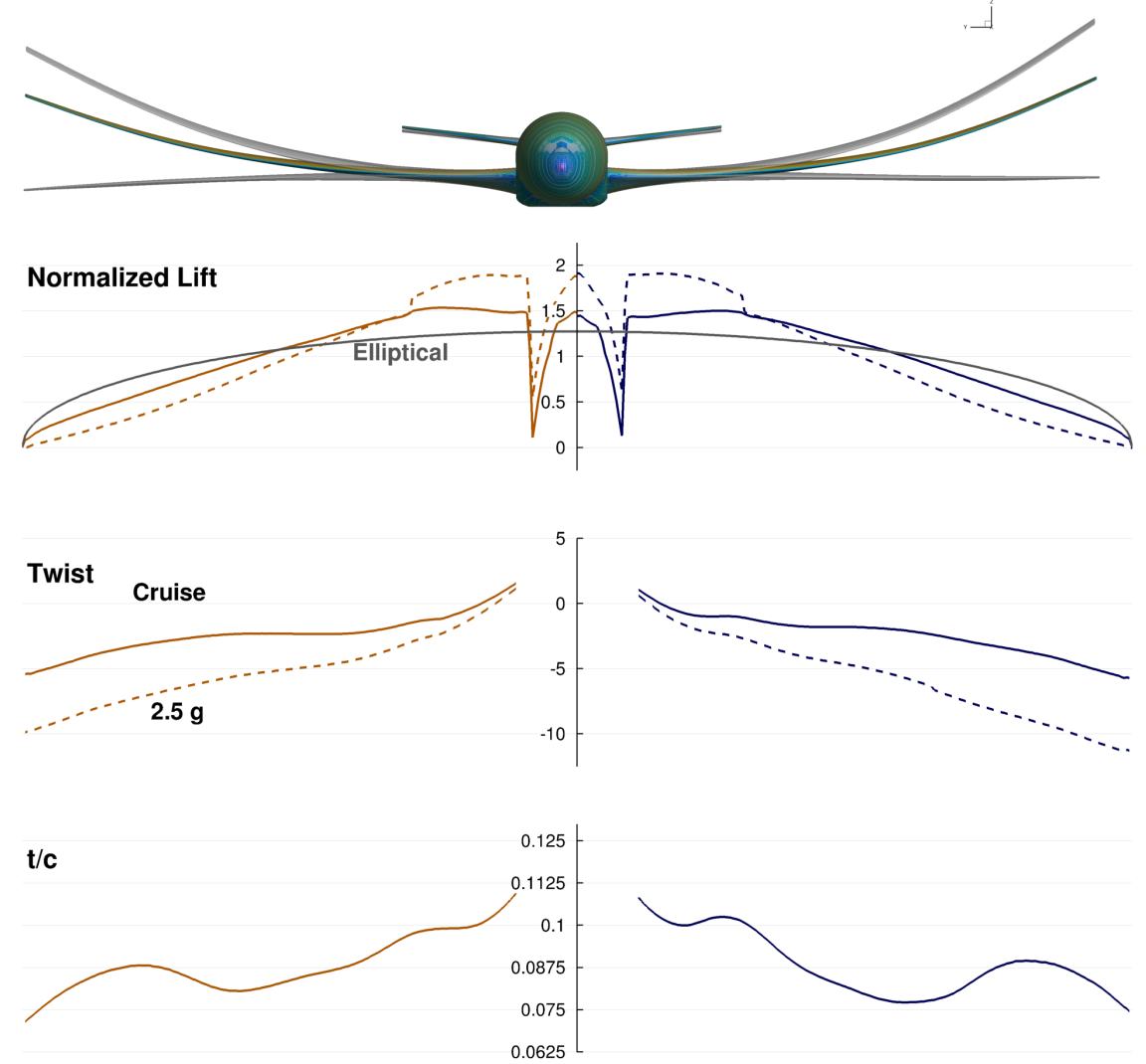

Avg. TOGW: $284013 \mathrm{~kg}$

Wing mass: $33825 \mathrm{~kg}$

Avg. L/D: 21.87$$
\text { ค }
$$
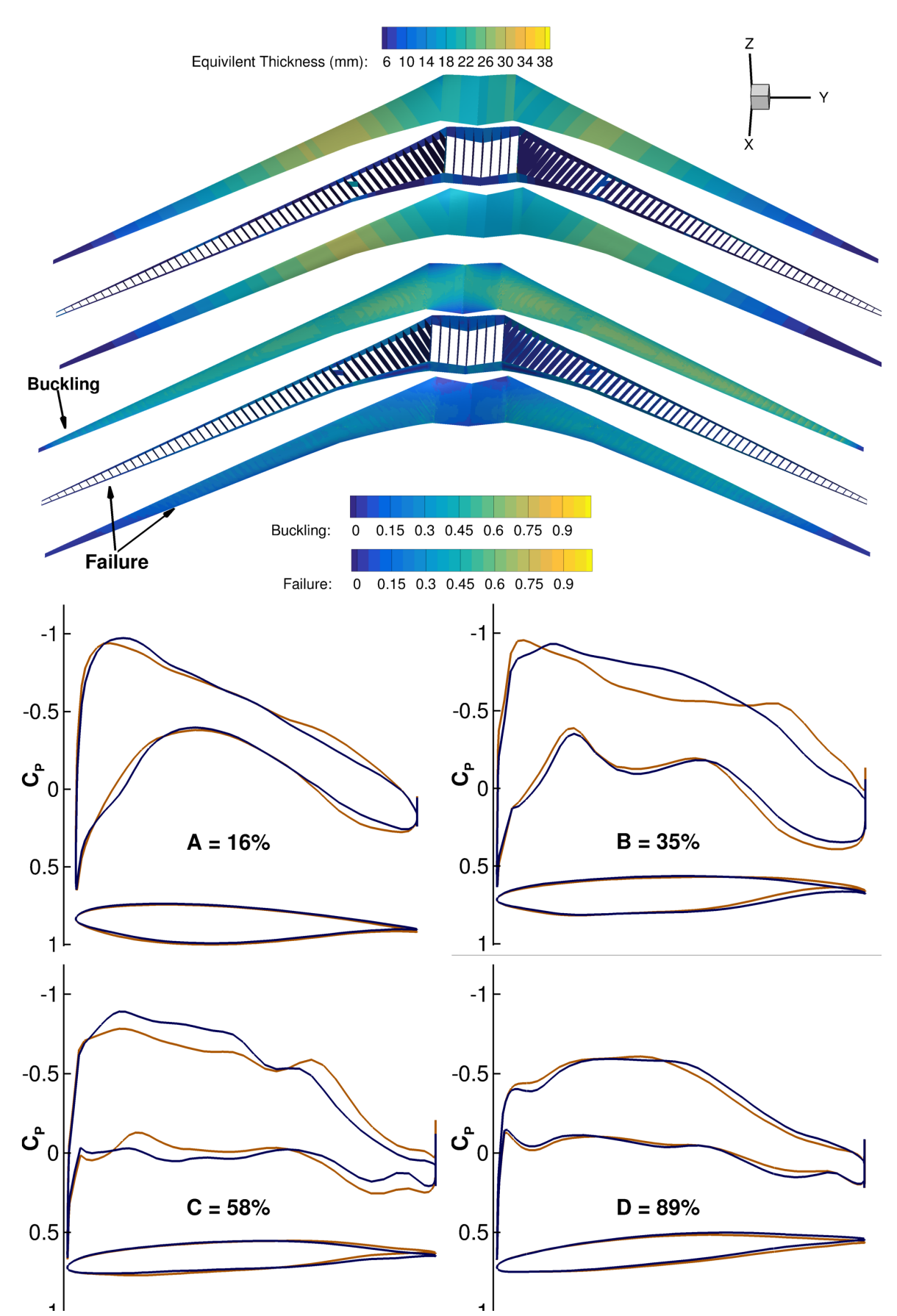

Figure 8. Comparison of baseline (left) versus optimized aluminum (right) aerostructural results 


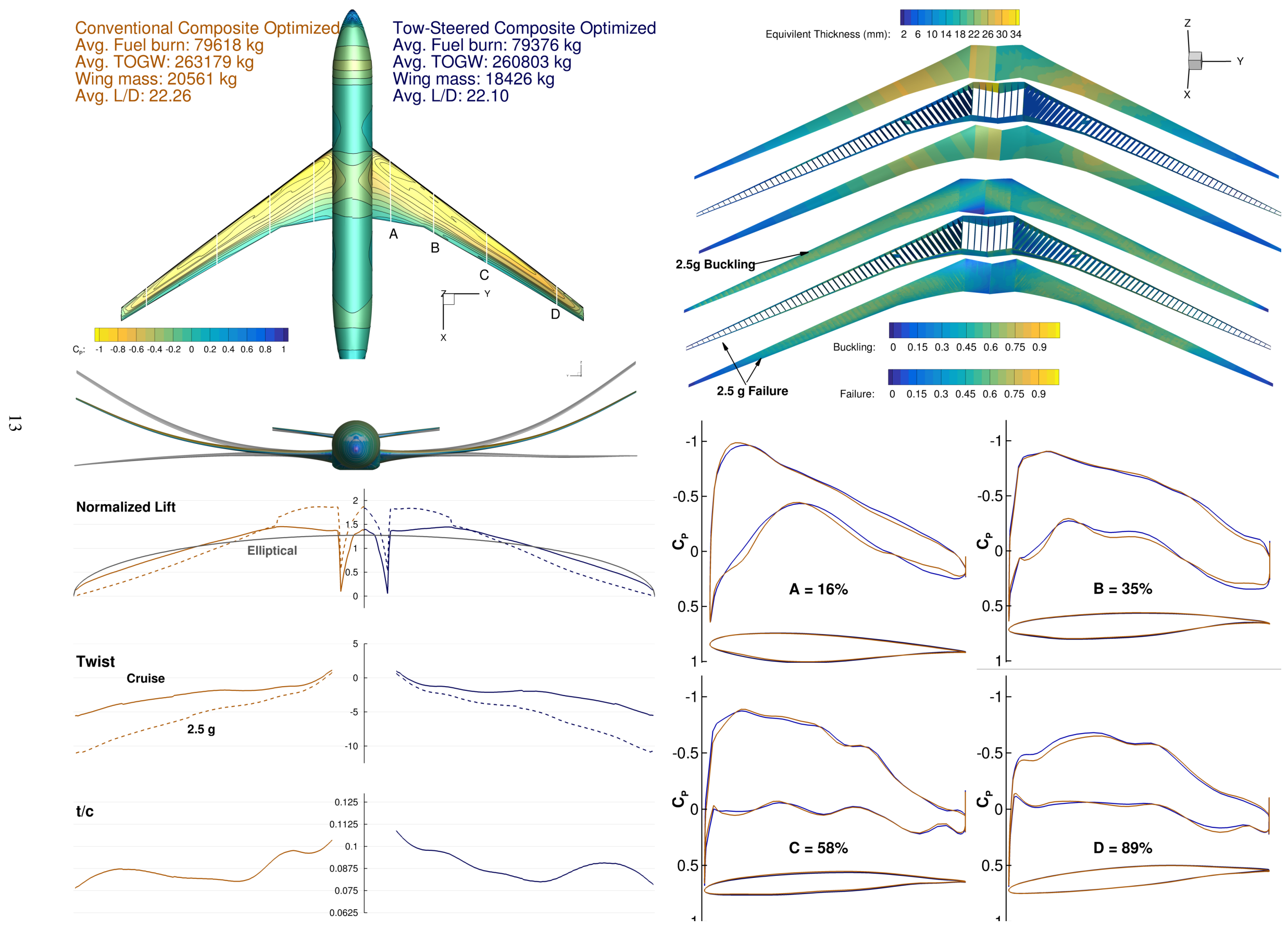

Figure 9. Comparison conventional (left) versus tow-steered (right) composite aerostructural optimization results 


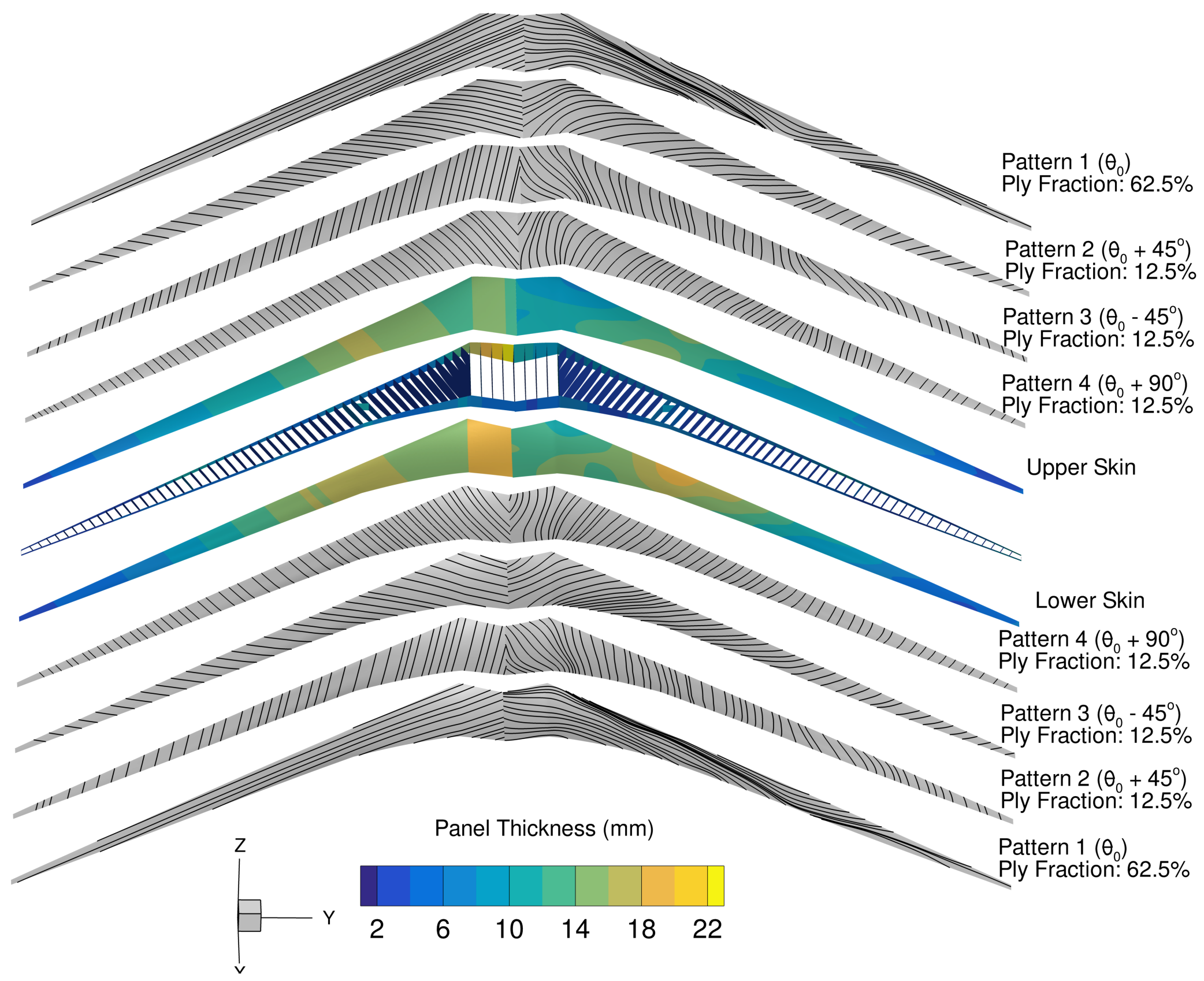

Figure 10. Comparison conventional (left) versus tow-steered (right) composite optimized layup results 


\section{Conclusions}

In this work we set up three multipoint aerostructural optimization problems: a conventional aluminum and composite and an unconventional tow-steered composite. Multiple design points were considered for the optimization to ensure more robust and realistic designs. The optimization problems were performed on a high aspect ratio wing geometry that features large aeroelastic deflection with tight coupling between aerodynamic and structural disciplines. We found that switching the wing material from aluminum to conventional composites yielded a reduction of $8.7 \%$ in fuel burn and a 39\% reduction in structural weight. Switching from a conventional composite design to a tow-steered design resulted in a more modest, but still noticeable, reduction of $0.4 \%$ in fuel burn, and a $10 \%$ reduction in structural weight. The results indicate that the patterns of the tow-steered design are driven by local effects, where the tow angles are tailored to align with the principal stress directions to be more efficient in satisfying buckling and failure constraints, as opposed to global effects, such as increasing bending-twist coupling for passive load alleviation.

\section{Acknowledgments}

The authors would like to acknowledge the support of NASA through award NNL15AA01C. This work was made possible by the Extreme Science and Engineering Discovery Environment (XSEDE), which is supported by the National Science Foundation grant number ACI-1053575. We would also like to thank Dr. Gaetan Kenway of the University of Michigan for his help in defining the uCRM-13.5 model; Dr. Bret Stanford of NASA Langley Research Center for his help in defining the non-structural mass parameters for the uCRM-13.5 structural model; and Benjamin Smith from Aurora Flight Sciences for his valuable insight into the manufacturing process of tow-steered composites.

\section{References}

[1] Kenway, G. K. W. and Martins, J. R. R. A., "Multipoint High-Fidelity Aerostructural Optimization of a Transport Aircraft Configuration,” Journal of Aircraft, Vol. 51, No. 1, January 2014, pp. 144-160. doi:10.2514/1.C032150.

[2] Kenway, G. K. W., Kennedy, G. J., and Martins, J. R. R. A., "Scalable Parallel Approach for High-Fidelity Steady-State Aeroelastic Analysis and Derivative Computations," AIAA Journal, Vol. 52, No. 5, May 2014, pp. 935-951. doi:10.2514/1.J052255.

[3] Kennedy, G. J., Kenway, G. K., and Martins, J. R. R. A., “A Comparison of Metallic, Composite and Nanocomposite Optimal Transonic Transport Wings," Tech. rep., NASA, March 2014, CR-2014-218185.

[4] C. Hvejsel, E. L. and Stolpe, M., "Optimization strategies for discrete multi-material stiffness optimization," Structural and Multidisciplinary Optimization, , No. 44, 2006, pp. 149-163.

[5] Kennedy, G. J. and Martins, J. R. R. A., “A Laminate Parametrization Technique for Discrete Ply Angle Problems with Manufacturing Constraints," Structural and Multidisciplinary Optimization, Vol. 48, No. 2, August 2013, pp. 379-393. doi:10.1007/s00158-013-0906-9.

[6] Jutte, C. V., Stanford, B. K., Wieseman, C. D., and Moore, J. B., "Aeroelastic Tailoring of the NASA Common Research Model via Novel Material and Structural Configurations," Proceedings of the AIAA 52nd Aerospace Sciences Meeting, January 2014. doi:doi:10.2514/6.2014-0598.

[7] Stodieck, O., Cooper, J. E., Weaver, P., and Kealy, P., Optimisation of Tow-Steered Composite Wing Laminates for Aeroelastic Tailoring, American Institute of Aeronautics and Astronautics, 2014/05/31 2014. doi:doi:10.2514/6.2014-0343.

[8] Stanford, B. K., Jutte, C. V., and Wieseman, C. D., "Trim and Structural Optimization of Subsonic Transport Wings Using Nonconventional Aeroelastic Tailoring,” AIAA Journal, Vol. 54, No. 1, Oct. 2015, pp. 293-309. doi:10.2514/1.J054244.

[9] Brooks, T. R., Kennedy, G. J., and Martins, J. R. R. A., "High-fidelity Aerostructural Optimization of a High Aspect Ratio Tow-steered Wing," 57th AIAA/ASCE/AHS/ASC Structures, Structural Dynamics, and Materials Conference, American Institute of Aeronautics and Astronautics, January 2016. doi:10.2514/6.2016-1179.

[10] Liem, R. P., Mader, C. A., and Martins, J. R. R. A., "Surrogate Models and Mixtures of Experts in Aerodynamic Performance Prediction for Mission Analysis," Aerospace Science and Technology, Vol. 43, June 2015, pp. 126-151, 10.1016/j.ast.2015.02.019.

[11] Burdette, D. A., Kenway, G. K., and Martins, J. R. R. A., "Performance Evaluation of a Morphing Trailing Edge Using Multipoint Aerostructural Design Optimization," 57th AIAA/ASCE/AHS/ASC Structures, Structural Dynamics, and Materials Conference, San Diego, CA, 01/2016 2016.

[12] Kennedy, G. J. and Martins, J. R. R. A., "Parallel Solution Methods for Aerostructural Analysis and Design Optimization," Proceedings of the 13th AIAA/ISSMO Multidisciplinary Analysis Optimization Conference, Fort Worth, TX, Sept. 2010, AIAA 2010-9308.

[13] Kenway, G. K. W., Kennedy, G. J., and Martins, J. R. R. A., "A Scalable Parallel Approach for High-Fidelity Aerostructural Analysis and Optimization," 53rd AIAA/ASME/ASCE/AHS/ASC Structures, Structural Dynamics, and Materials Conference, Honolulu, HI, April 2012, AIAA 2012-1922. 
[14] Liem, R., Kenway, G. K. W., and Martins, J. R. R. A., "Multimission Aircraft Fuel Burn Minimization via Multipoint Aerostructural Optimization,” AIAA Journal, Vol. 53, No. 1, January 2015, pp. 104-122. doi:10.2514/1.J052940.

[15] van der Weide, E., Kalitzin, G., Schluter, J., and Alonso, J. J., "Unsteady Turbomachinery Computations Using Massively Parallel Platforms," Proceedings of the 44th AIAA Aerospace Sciences Meeting and Exhibit, Reno, NV, 2006, AIAA 20060421.

[16] Mader, C. A., Martins, J. R. R. A., Alonso, J. J., and van der Weide, E., “ADjoint: An Approach for the Rapid Development of Discrete Adjoint Solvers,” AIAA Journal, Vol. 46, No. 4, April 2008, pp. 863-873. doi:10.2514/1.29123.

[17] Lyu, Z., Kenway, G. K., Paige, C., and Martins, J. R. R. A., "Automatic Differentiation Adjoint of the Reynolds-Averaged Navier-Stokes Equations with a Turbulence Model," 21st AIAA Computational Fluid Dynamics Conference, San Diego, CA, Jul 2013. doi:10.2514/6.2013-2581.

[18] Kennedy, G. J. and Martins, J. R. R. A., “A Parallel Finite-Element Framework for Large-Scale Gradient-Based Design Optimization of High-Performance Structures," Finite Elements in Analysis and Design, Vol. 87, September 2014, pp. 56-73. doi:10.1016/j.finel.2014.04.011.

[19] Kennedy, G. J. and Hicken, J. E., "Improved Constraint-Aggregation Methods," Computer Methods in Applied Mechanics and Engineering, Vol. 289, 2015, pp. 332-354. doi:10.1016/j.cma.2015.02.017.

[20] Kennedy, G. J., "Strategies for adaptive optimization with aggregation constraints using interior-point methods," Computers \& Structures, Vol. 153, 2015, pp. 217-229. doi:10.1016/j.compstruc.2015.02.024.

[21] Uyttersprot, L., Inverse Distance Weighting Mesh Deformation, Ph.D. thesis, Delft University of Technology, 2014.

[22] Brown, S. A., "Displacement Extrapolation for CFD+CSM Aeroelastic Analysis," Proceedings of the 35th AIAA Aerospace Sciences Meeting, Reno, NV, 1997, AIAA 1997-1090.

[23] Gill, P., Murray, W., and Saunders, M., "SNOPT: An SQP algorithm for large-scale constraint optimization," SIAM Journal of Optimization, Vol. 12, No. 4, 2002, pp. 979-1006.

[24] Perez, R. E., Jansen, P. W., and Martins, J. R. R. A., "pyOpt: a Python-Based Object-Oriented Framework for Nonlinear Constrained Optimization," Structural and Multidisciplinary Optimization, Vol. 45, No. 1, January 2012, pp. 101-118. doi:10.1007/s00158-011-0666-3.

[25] Vassberg, J. C., DeHaan, M. A., Rivers, S. M., and Wahls, R. A., "Development of a Common Research Model for Applied CFD Validation Studies," 2008, AIAA 2008-6919.

[26] Kenway, G. W. K. and Martins, J. R. R. A., "High-fidelity aerostructural optimization considering buffet onset," Proceedings of the 16th AIAA/ISSMO Multidisciplinary Analysis and Optimization Conference, June 2015.

[27] Kennedy, G. J., Kenway, G. K. W., and Martins, J. R. R. A., "High Aspect Ratio Wing Design: Optimal Aerostructural Tradeoffs for the Next Generation of Materials," Proceedings of the AIAA Science and Technology Forum and Exposition (SciTech), National Harbor, MD, January 2014, AIAA-2014-0596.

[28] Akgün, M. A., Haftka, R. T., Wu, K. C., Walsh, J. L., and Garcelon, J. H., "Efficient Structural Optimization for Multiple Load Cases Using Adjoint Sensitivities," AIAA Journal, Vol. 39, No. 3, 2001, pp. 511-516.

[29] Poon, N. M. K. and Martins, J. R. R. A., "An Adaptive Approach to Constraint Aggregation Using Adjoint Sensitivity Analysis," Structural and Multidisciplinary Optimization, Vol. 34, No. 1, July 2007, pp. 61-73. doi:10.1007/s00158-0060061-7.

[30] Gill, P. E., Murray, W., and Saunders, M. A., “An SQP algorithm for large-scale constrained optimization,” Society for Industrial and Applied Mathematics, Vol. 47, No. 1, 2005.

[31] Kennedy, G. J. and Martins, J. R. R. A., “A parallel aerostructural optimization framework for aircraft design studies,” Structural and Multidisciplinary Optimization, Vol. 50, No. 6, December 2014, pp. 1079-1101. doi:10.1007/s00158-014-1108-9. 